\title{
Tying Legitimacy to Political Power: \\ Graded Legitimacy Standards for International Institutions
}

\author{
Antoinette Scherz*
}

\begin{abstract}
International institutions have become increasingly important not only in the relations between states, but also for individuals. When are these institutions legitimate? The legitimacy standards for international institutions are predominantly either minimal or democratic and cannot capture the large variety of international institutions. This paper develops an autonomy-based conception of legitimacy based on the justification of political power that is applicable to both international and domestic institutions. Political power as rule-setting is a particular normative threat to the personal and political autonomy of its subjects. The more political power an institution exercises, the more demanding the legitimacy standards it needs to fulfill in order to be legitimate. The paper argues that an increase in the four dimensions of political power (scope, domain sensitivity, applicability, and impact) raises the legitimacy burden for the institution. Finally, graded legitimacy standards are proposed. These are sensitive to the differences between international institutions in respect of their levels of political power, i.e. level of competences. In contrast to minimal or democratic legitimacy standards, the paper suggests that different standards of accountability, participation, and human rights have to be fulfilled according to the institution's level of political power.
\end{abstract}

Keywords: international organizations, authority, binding rules, levels of competences, comparative benefit

\footnotetext{
${ }^{*}$ Postdoctoral Fellow, PluriCourts, University of Oslo. This work was partly supported by the Research Council of Norway through its Centres of Excellence funding scheme, project number 223274. I am grateful for the feedback of the participants of the Workshop "Authority, Legitimacy, Democracy," Free University Berlin 2015, the Conference "The Challenges of Global Pluralism," Frankfurt 2015 and the ECPR General Conference Panel "Political Legitimacy, Political Order, and Institutional Stability" Bordeaux 2013 as well as the participants of the International Political and Legal Theory Seminar in Oslo and the Political Theory Colloquium in Frankfurt. In particular, I would like to thank Nate Adams, Andreas Follesdal, Eszter Kollar, Merten Reglitz, Martin Westergren, and the anonymous reviewers for their constructive comments.
} 


\section{INTRODUCTION}

The legitimacy of international institutions has become an issue of growing importance as more and more states delegate competences to international institutions. In recent contributions to the relevant debates, the concept of legitimacy as a "right to rule" (cf. Raz, 1986) has also been applied to international institutions (e.g. Buchanan, 2010; Tasioulas, 2010; Besson, 2014). The legitimacy standards demanded of international institutions are predominantly either minimal or extrapolated from domestic state standards. Minimal standards focus mainly on output, human rights or transparency (e.g. Majone, 2000; Buchanan and Keohane, 2006; Ratner, 2015), while state-based standards are often very demanding, requiring that democratic standards be met (e.g. Held, 1995; Archibugi and Held, 1995; Patomäki, 2003; Von Bogdandy and Venzke, 2012). Finally, many legitimacy standards found in the literature apply only to one particular international institution (e.g. Føllesdal and Hix, 2006; Howse and Nicolaïdis, 2003). While I do not necessarily disagree with the proposed standards for specific institutions, these strands of legitimacy accounts exhibit at least one of two shortcomings. First, since international institutions differ greatly with regard to their purpose and the political power they exercise, common sense assessments of their legitimacy seem to take it for granted that different legitimacy standards are appropriate across international institutions. In the public debate one can observe that the more authority, or in my own terms political power, an international institution has, the more it is politicized and the more legitimation struggles it faces (e.g. Stein, 2001; Zürn et al., 2012). This means that the more powerful the institutions, the more demanding the necessary legitimacy standards. Therefore, the fact that existing accounts of international institutions' legitimacy cannot provide a systematic theory of why different standards should apply to such different institutions seems at least puzzling if not worrying.

Second, if we take legitimacy to provide standards that guide our action - in particular, our compliance with specific institutions in order to address the problems that we face beyond the state - then these accounts are insufficient. In a world of vastly different international institutional options, legitimacy accounts that are not sensitive to these differences encounter difficulties in prescribing actions since they are either overly critical or not critical enough, leaving no clear course of action or too many courses of action. In this sense, democratic standards are too demanding if no international institution can be legitimate in light of the current state system, while minimal accounts cannot address existing worries in the public sphere about the influence of international institutions.

This paper seeks to provide an overarching framework that explains why differences in political power among international institutions require different legitimacy standards. It develops an account that accommodates such variation as there is - between the International 
Telecommunication Union and the UN Security Council - by arguing that legitimacy standards depend on the political power of the institution(s) in question. Allen Buchanan's metacoordination view of legitimacy goes some way towards achieving this aim. It explains variation in legitimacy criteria in terms of the risks and benefits that an institution generates (Buchanan, 2013: 188-191). However, what kind of risks and benefits should be considered? In order to answer this question, this article starts from the perspective of what makes democratic states legitimate. Democratic systems establish and protect the equal autonomy of their citizens through and from political power. ${ }^{1}$ Therefore, I propose an autonomy-based conception of legitimacy that evaluates the legitimacy of institutions according to the risks and benefits that their political power creates in respect of autonomy. From this perspective, legitimacy standards need to render the capacity of a particular international institution to influence autonomy assessable and controllable. Depending on the levels of political power that they exercise, international institutions require standards of human rights as preconditions for autonomy, as well as accountability and participation standards.

The argument proceeds in four steps. The first part of the article discusses why political power exercised through the setting and application of rules requires legitimation. It proposes an autonomy-based conception of legitimacy that links legitimacy to the risks and benefits an institution generates for autonomy. In the second part, I outline different dimensions of political power through rule-setting and show why they are normatively significant in terms of institutional legitimacy. In the third part, I propose to distinguish between three levels of political power for international institutions. The fourth part develops an account of legitimacy with graded standards for different international institutions according to their political power. In contrast to the mainstream arguments that international legitimacy ought to be democratic or minimal, I identify different standards of human rights, accountability, and participation, which have to be fulfilled across all three levels of international institutions' political power, while broad transparency and comparative benefits serve as preconditions for legitimacy.

This article contributes to the discussion of legitimacy within and beyond the state in two ways: First, it provides a framework for the legitimacy standards of specific international institutions by outlining a graded account with different normative standards of legitimacy dependent on the institution's political power. However, the relation between the extent of power and the requirement of more demanding standards should not be understood as a strict correlation. Rather, the specific standards of each international institution have to be refined by taking into account its particular

\footnotetext{
${ }^{1}$ My argument is compatible with both a liberal and a republican understanding of democracy. From a liberal perspective, the exercise of political power is problematic if it restricts the status of those subjected as free and equals, while from a republican point of view it sees domination as the capacity to arbitrarily interfere, if it is not under shared control (cf. Rawls, 1971; Pettit, 1997).
} 
purpose and political power. Therefore, the paper outlines questions for future research about the legitimacy standards of particular international institutions. Second, the paper contributes to the discussion about what constitutes a legitimate international order by taking into account the division of labor between states and international institutions when specifying legitimacy standards. International institutions cannot carry the burden of establishing a legitimate international or global political order on their own. Instead, they rely on legitimate political processes within states, while the legitimacy of states simultaneously requires international institutions that enable legitimate interactions between states and between states and other actors. On the one hand, in the short and medium term, states remain the primary locus of democracy. This democratic decision-making needs to be protected, but it need not be replicated on the international level. Rather, a multilevel system of legitimacy that takes the responsibly of states into account is required. On the other hand, insofar as international institutions take over competences, they should not be treated as bureaucratic systems, but rather as having authority. This shift of competences limits the capacity of states to protect individuals' autonomy and, in turn, appropriate standards for international institutions are necessary to guarantee this protection.

\section{POLITICAL POWER REQUIRING LEGITIMATION}

First, it should be noted that legitimacy has both a descriptive (sociological) and a normative meaning. The descriptive aspect of legitimacy, as Max Weber defines it, refers to the social acceptance of authority, i.e. the institution is believed to be legitimate (Weber, 1964). ${ }^{2}$ The normative understanding of legitimacy refers to the justification of political power or authority, often understood as the "right to rule" establishing demands of compliance. This article focuses on normative legitimacy and defines the concept of legitimacy as follows: an institution has the right to rule, i.e. it is legitimate, if there are weighty content-independent reasons to comply for those subjected to it, and reasons not to interfere for those outside the institution. ${ }^{3}$ This concept of legitimacy as the right to rule applies to institutions exercising political power both within and beyond the state.

Institutions include both formal and informal institutions that function through rules or informal norms that define roles (with respective rights and duties), stabilize expectations, and apply social or legal sanctions. Informal norms - for example, sexist or racist norms - might be as severe in their

\footnotetext{
${ }^{2}$ These aspects of legitimacy are connected to one another especially in democracy (cf. Beetham, 1991).

${ }^{3}$ This formulation draws on both Buchanan (2010) and Raz's (1986) definition of legitimacy. I will not address the question of whether these reasons are weighty or exclusionary since this does not affect the argument.
} 
consequences and often harder to change than formal laws. My focus here, however, is specifically formal institutions, since they explicitly claim compliance. I will refer to these kinds of institutions that make such claims to compliance, or seek to set binding rules, as political institutions. Political power is defined as rule-setting authority or competences, including the application and possibly some form of enforcement of rules (henceforth, "competences" for short).

So, political institutions claim to set binding rules, but such rules are only normatively binding if the institution is legitimate. In this case the institution changes the normative relationships of its subjects, namely their rights and duties. Therefore, legitimacy as the right to rule should be understood as a power-right in the Hohfeldian sense, not just as a mere liberty- or claim-right. To define the concept of legitimacy as power-right is not a new claim (see Applbaum, 2010; Christiano, 2012; Reglitz, 2015); however, from this concept it follows that the extent of political power that an institution exercises defines the required legitimacy standards for the institution. These standards can be understood as characteristics of the institution that provide weighty contentindependent reasons for compliance. Therefore, the main claim of this article is that the appropriate legitimacy standards of an institution depend on the extent of political power exercised by it. The more political power an institution exercises, the more demanding the legitimacy standards it needs to fulfill in order to be legitimate. For example, if an institution exercises rule-setting competences over a larger domain or more important issues, the standards should be more demanding compared to a less powerful institution. This account is particularly useful in determining the legitimacy standards of international institutions because there is such variation between them. The account developed herein demonstrates how legitimacy standards should vary for international institutions by taking political power as requiring legitimation.

In addition to an institution's political power, its purpose also needs to be taken into account to define the relevant legitimacy standards (e.g. Adams et al., 2019; Adams, 2019). An institution's political power and purpose are mutually dependent as specific competences are required to achieve a particular purpose, and vice versa. The institutional purpose can require specific legitimacy standards because it determines the kind of institution. For example, if the purpose of courts is to judge cases justly, independence is an important requirement. In this article, I will leave aside the purpose of the institution and focus on why different levels of political power or competences require different legitimacy standards. In order to establish what kind of reasons an institution needs to provide and how it can provide them, a specific conception of legitimacy is required. 
Assuming that political power and autonomy stand in a particular relationship to each other, I will argue for an autonomy-based conception of legitimacy, which specifies the risks and benefits of political power for autonomy. This conception can account for two threats to political institutions namely individual and political autonomy - while other conceptions often struggle to account for both aspects or are of limited help in determining specific legitimate standards. I illustrate this issue by discussing two of the best-known legitimacy conceptions, Joseph Raz's service conception and Allen Buchanan's metacoordination view. Raz's service conception is based on the so-called normal justification thesis, which states that an institution or person has legitimate authority over someone if the latter is likely to comply better with the reasons that apply to her by following the directives of the authority, than by trying to follow the reasons that apply to her directly (Raz, 1986: 53). This instrumental account raises concerns that its conception of legitimacy cannot account for why we value democratic procedures intrinsically due to their fairness (e.g. Hershovitz, 2003: 219). Others have argued that the service conception can account for the fairness of procedures in the reasons relevant for legitimate authority (e.g. Raz, 2006; Tasioulas, 2010; Viehoff, 2011). This seems plausible, but if it is so, the Razian conception seems underdetermined, as it does not specify the reasons that are the basis for legitimate authority. ${ }^{4}$ As such, either it cannot account for the intrinsic value of democratic procedures, or it is too vague.

An alternative to the service conception is Buchanan's metacoordination view of legitimacy (Buchanan, 2013: 178-180; 2018). The metacoordination view understands legitimacy as establishing whether an institution is worthy of our moral reason-based support. The practical function of legitimacy assessments is to enable coordination through particular institutions by converging on public legitimacy standards. Buchanan argues that legitimacy evaluations are moral reason-based judgments about the risks and benefits of empowering an institution. This conception specifies the way we should assess the legitimacy of an institution in two ways: 1) legitimacy needs public standards to enable coordination; 2) the legitimacy of an institution depends on the risks and benefits of empowering it. Yet, what kind of risks and for whom? According to Buchanan, this evaluation needs to be moral reason-based and depends on both the institution and the background conditions. This specifies the requirements for legitimacy to some degree, but regarding institutions that demand compliance with their rules, i.e. political institutions, the risks and benefits can be specified further by looking at the particular relationship between political power and autonomy.

\footnotetext{
${ }^{4}$ For a discussion of this issue see also Buchanan (2018: 70ff.). However, in contrast to Buchanan, I follow Raz's concept insofar as I regard the question of legitimacy as particularly relevant for institutions that claim authority.
} 
Therefore, I propose a specific autonomy-based conception of legitimacy that judges the legitimacy of political institutions on the basis of the risks and benefits to the autonomy of those subject to the rules and those affected by them.

The focus of the autonomy-based conception of legitimacy captures the particular normative risks and benefits of political power for autonomy. Rule-setting is normatively significant as it has the capacity to systematically influence the lives of others. Political institutions are necessary to enable coordination and equal autonomy, yet in turn they themselves become a severe threat to individuals' autonomy. This influence of political power is dual: on the one hand, it is necessary for the robust protection of individual freedom of choice (Pettit, 2012: Chapter 1); on the other, it concerns the status of its subjects as equal normative authorities (Forst, 2015) or, as I call it, normgivers. In other words, political power affects both personal and political autonomy (Habermas, 1996: Chapter 3; Forst, 2012: 125-137). Personal autonomy means that an individual is the author of her own life by choosing and shaping her future. Political power shapes expectations, creates social pressure, and has the capacity to influence individuals' scope of opportunities. Therefore, it influences our capacity to shape our life plans as norm-givers in systematic ways. While a minimum of options is necessary to act autonomously (Raz, 1986: 369), such personal autonomy is incomplete if it is not accompanied by interpersonal political autonomy. Political autonomy goes beyond having a sufficient option set and requires the status of norm-giver to be reciprocally recognized and treated as such in one's political communities and institutions. The institutionalization of political autonomy requires equal control as a norm-giver over the rules to which one is subjected, or in other words a form of co-authorship.

The capacity of political institutions to influence the lives of others systematically through rulesetting relates to both aspects of autonomy: they affect a broad array of options and they institutionalize the status of norm-givers. The political power of international institutions works in the same manner, but if the international system is a multilevel one with states institutionalizing political autonomy, this also moves the problem up a level. International institutions might not only undermine (or foster) the personal and political autonomy of individuals, but the allocation of rulesetting competences on the international level can also affect states' capacity to protect autonomy. Nominally individuals might have rights within their states that realize their political autonomy, but the rules of the international institution might restrict the decision-making realm. Of course, the influence of international institutions can be positive for autonomy as well; however, the capacity to influence autonomy requires legitimation.

Since political power is directly linked to the realization of political autonomy, one might expect an all-subjected principle for its legitimacy standards. This is plausible considering who should have reasons to comply, namely those to whom the rules are addressed. However, beyond the 
simplified closed system of a state, domestic or international rules may have effects beyond their "jurisdiction". These effects consist in both intended and unintended externalities. Only being affected by but not subjected to a rule that one has not co-authored seems less problematic. While it is true that rules do not demand compliance outside of their jurisdiction and thus do not constitute a problem for political autonomy, they seek to establish a claim to non-interference. If the external effects of rules are drastic - either for the personal autonomy of those affected or insofar as they threaten the basic conditions for their political autonomy - they are also relevant for the legitimacy of the issuing political institution. Detrimental effects to the autonomy of outsiders will also affect the reasons to comply for insiders. The autonomy-based account of legitimacy can, therefore, explain why both an all-subjected principle and the all-affected principle apply yet with regarding the creation of different reasons - namely compliance and non-interference. This also explains why institutions need to fulfill different legitimacy standards for those subjected and affected.

\section{Political Power as Rule-setting, Application and Enforcement}

The need for institutions that wield political power to meet standards of legitimacy has traditionally been grounded in the fact that wielding political power corresponds to the monopoly of coercive power (Locke, 1980; Blake, 2001). From the perspective of autonomy this aspect of political institutions requires justification, but other aspects of the creation and maintenance of rules are not unproblematic either. The authority that political institutions exercise and the set of normative problems it raises are distinct from those of distribution or brute force, since they include an appeal to compliance usually exercised through directives or rules (cf. Raz, 1986: 24-27). This may not sound as problematic as the use of coercive force. However, political power requires legitimation since its rules and their application seek to change the normative relationships, i.e. rights and duties, of those subjected to them. Only if an institution is legitimate - if it is overall beneficial for equal individual and political autonomy - does it succeed in actually changing the relationships in question. This means the exercise of political power should be understood as the creation, application, and enforcement of rules. This includes the function of all branches of government whose actions are embedded and simultaneously create a system of rules that exercises power, which is political. The coercive function of political power - for example, through the police force - is only one part of a whole system that requires legitimation. Even though on the international level these functions of rule-setting and application are dispersed throughout different institutions, they exercise political power because they are systemic, creating a system of rules and making claims to compliance. 
Since legitimacy is not just an abstract ideal but supposed to guide our actions - in particular, our compliance - it should also tell us if we should comply. In this regard, there are two questions concerning the legitimacy of political institutions: 1) When is an institution legitimate? 2) How do we know if it is legitimate or not? Being able to know whether an institution creates risks or benefits is essential for the metacoordination function of legitimacy. However, the legitimacy and the knowledge of an institution's legitimacy might still diverge. Yet if we take the political side of autonomy seriously, procedural standards that allow for control over rule-setting are essential. This means that certain transparency, accountability, and participation standards, which establish control over rule-setting and maintenance, are not just an epistemic feature but constitutive of legitimacy. Other standards such as human rights should secure a certain level of individual autonomy. In order to determine the appropriate standards for an institution, we first need to know the capacity of an institution to influence autonomy, i.e. its political power. Second, depending on the extent of political power, more or less demanding standards are needed to control the risks it generates, particularly those that arise in the domain of political autonomy. All institutions need to produce comparative benefits with regard to the non-institutional and certain institutional alternatives; otherwise there is no reason to create the risk of empowering a political institution. I will turn to these legitimacy standards in part four. Let me now discuss how the extent of political power can vary in different dimensions.

\section{DIMENSIONS OF POLITICAL RULE-SETTING POWER}

The extent of political power or rule-setting competences held by any particular international institution relates to its capacity to influence the equal autonomy of others by restricting the range of their life choices and status as norm-givers. Since power through rule-setting is what is relevant here, this concerns both what an institution can set rules about and how they apply. This can be captured by four dimensions: 1) scope; 2) domain sensitivity; 3) applicability; and 4) impact. An increase in any of these dimensions raises the legitimacy burden for the institution.

First, the scope of issues regarding which institutions can set rules is essential in gauging the extent to which rule-setting can affect the lives of those subjected by restricting the range of options available. The issues under the purview of international institutions range from narrow to broader ones. The question of scope is important as it establishes the legitimacy for particular actors or institutions. While it is true that the European Union's (EU) competence to decide on many issues has the same intrusive effect as the sum of many institutions making the same decisions, it is important to know which actors we should hold accountable. In particular, the accumulation of political power creates a threat to the equal autonomy of individuals. On the level of the 
international system, the question of legitimacy arises again and a fragmented system that generates unjustified, cumulative effects might require the establishing of institutions and procedures that can legitimize them. The legitimacy standards for particular institutions and the legitimacy of the whole system are both relevant factors to question, but they should be kept separate for the sake of clarity and concrete institutional reforms.

Second, domain sensitivity captures how important the domain over which rules are set is for the lives of those subjected. While the importance or sensitivity of these domains varies to some degree for every person and their respective life plans, we can assume that certain aspects are essential to all human beings and are generally what human or constitutional rights seek to protect. Therefore, the difference in this dimension reaches from mainly technical issues to fundamental human rights. ${ }^{5}$ For example, driving on one side of the road does not raise the same normative concerns as rules about marriage, as it does not affect the equal autonomy of those subjected in the same way. However, an accumulation, i.e. a wider scope of technical or coordinative rule-setting competences, may also restrict and shape individuals' opportunity space. If they do so in an encompassing way, they raise similar problems as institutions with competences concerning more sensitive domains. For example, the EU was for a long time framed as a technical or coordinative institution. Though today most would agree that it has moved far beyond the technical domain, even in earlier days the density of rules would have made a technical domain classification questionable.

Third, the applicability of rules can be distinguished as direct or indirect, in terms of whether or not an institution's rule-setting power is mediated through states. This makes a difference because it means that the authority of the international institution is restrained by an additional level of control, namely the domestic political processes, and therefore on how individuals are subjected to its rule-setting. If rules can only be applied indirectly, states must first ratify and implement them. Direct or immediate applicability of rules, on the other hand, means that rules need not be implemented by states in order to apply to firms, individuals or states. Furthermore, it implies that individuals may immediately invoke certain rules promulgated by an international institution before a national or international court (see footnote 6 below). An international institution might expand or restrict the options available to individuals, but how it affects their capacity to decide as equals on available opportunities depends on how they can participate in the political decision-making that sets the rules guiding the society in which they live. The domestic democratic procedures are the most important means through which this political participation is institutionalized and should

\footnotetext{
${ }^{5}$ Even if an institution has only technical or coordinative rule-setting power, the issue of legitimacy may still arise. The way in which different technical issues relate and need to be handled is often up for debate and therefore political and relevant to legitimacy.
} 
therefore not be sidestepped without a replacement. The same problem as the one caused by direct effect is created by institutions that can, in cases of conflict, override existing national laws in contrast to institutions that can only give recommendations.

Fourth, the impact of an institution concerns how it actually affects individuals and states through the rules it sets. The impact of an institution therefore considers unintended effects and effects that are external to the institution's jurisdiction. While the capacity to affect the autonomy of others is normatively relevant and therefore what the other three dimensions are concerned with, looking at the impact provides a measure to correct the institutional power in cases where the capacity was underestimated.

Generally, it is important to classify an international institution according to the power that it actually possesses and not the one it claims to hold according to its official statements or documents. In this way, the dimensions should capture if the exercise of the institution's rulesetting authority exceeds its claimed one. This may particularly be the case for impact but it is also true for the other dimensions. For example, regarding applicability, if it is very costly and almost impossible for certain states not to comply with the rules or recommendations of an international institution, the de facto applicability of its rule-setting is direct.

\section{LEVELS OF POLITICAL POWER FOR INTERNATIONAL INSTITUTIONS}

The dimensions of rule-setting competences outlined above can be used to define different levels of political power of international institutions. How to weigh the increase or decline in the different dimensions requires more detailed debate. The aim of this paper is more modest, as I argue only that it is possible to distinguish three broad levels of political power.

The lowest level is defined by a minimum in all four dimensions. In my view, international organizations with narrow and precisely specified rule-setting competences that only concern technical and coordinative issues (e.g. the International Telecommunication Union) fall under the first category. This is a strongly restricted level because if an institution's political power exceeds the minimum in only one of the four dimensions, it falls on a higher competence level. For example, it is already questionable whether the International Organization for Standardization can still be attributed to the lowest level, since its standardizations concern a broad range of products and topics (scope) and the impact they have goes beyond technical issues (domain sensitivity).

On the other end of the spectrum are institutions whose rule applicability is direct and that have at least a high level in one of the other dimensions of political power. This means that they set rules over a large scope of issues, a sensitive domain or whose impact is high. These institutions can be classified as high-level competence institutions. The EU satisfies the criteria of the third level, since 
its members delegate a broad range of rule-setting competences to the European level and, as the European Court of Justice has pointed out in its landmark decision Van Gend en Loos, European Law can be directly applied, i.e. has direct effect. ${ }^{6}$ Other international institutions such as certain UN agencies, in particular the de-listing procedures, peace-enforcement and arguably even conditional loans, might be other instances of institutions with direct rule applicability. Such institutions require further careful evaluation. Between these two extremes of political power lies a vast range of medium competence institutions that exceed the minimum of technical institutions either in scope, domain or impact, but whose scope of rules applicability remains indirect.

In principle, every international institution can be classified according to the three categories outlined above. However, in practice, a detailed analysis is required to assign an international institution to a certain category. Such an analysis can only be carried out at the empirical level. These levels only provide a general framework for the standards of legitimacy of international institutions that I develop below. However, the standards that should be applied to a particular institution need to be further specified according to its purpose and specification of competences.

The purpose of an institution influences the required legitimacy standards. ${ }^{7}$ On the one hand, the competences an institution requires depend on the purpose it serves. This purpose itself has to be minimally moral for the institution to be legitimate. For example, a guild of assassins can never be legitimate no matter how democratically organized it is. In order for an institution to be legitimate, its competences have to correspond to its purpose, and it has to fulfill stronger standards of legitimacy the more competences it has. On the other hand, the purpose of an institution has further influence on the required legitimacy standards since some standards are function specific. For example, the purpose of international courts may relax the requirements of accountability in favor of impartiality considerations. A full analysis also needs to empirically observe the competences of the court and see whether they are in fact also exercising legislative functions. Only then can the appropriate legitimacy standards be established.

\section{GRADED STANDARDS OF LEGITIMACY FOR INTERNATIONAL INSTITUTIONS}

Which standards should apply to international institutions with different levels of political power? While I argue for broad transparency and comparative benefits as minimal conditions for all

${ }^{6}$ Case 26/61, NV Algemene Transporten Expeditie Onderneming van Gend en Loos v Nederlandse Administratis der Belastingen [1963] ECR 1.

${ }^{7} \mathrm{I}$ am referring to the purpose of an institution in an interpretive way that does not just consist of the aim that the founders had in mind (cf. Mitchell, 2008; Shany, 2014; Squatrito et al., 2018: 21). 
international institutions, the remaining standards should apply in a graded form. For the standards for every level outlined below, one should bear in mind that the requirements for the lower levels also apply to the higher ones and are in this way accumulative. Table 1 illustrates the required standard of legitimacy for the three levels of competences of international institutions.

Table 1: Legitimacy of International Institutions

\begin{tabular}{|c|c|c|c|}
\hline Competences of & \multicolumn{3}{|c|}{ Standards of legitimacy } \\
\hline & Human rights & Accountability & Participation \\
\hline High & Protect human rights & $\begin{array}{l}\text { Representational } \\
\text { structure through } \\
\text { democratic states }\end{array}$ & $\begin{array}{l}\text { Individual and state } \\
\text { participation rights }\end{array}$ \\
\hline Medium & Promote human rights & Contestation rights & Deliberation rights \\
\hline Low & Respect human rights & $\begin{array}{c}\text { Democratic state } \\
\text { consent }\end{array}$ & - \\
\hline $\begin{array}{l}\text { Preconditions of } \\
\text { legitimacy }\end{array}$ & & $\begin{array}{l}\text { Broad transparenc } \\
\text { Comparative benef }\end{array}$ & \\
\hline
\end{tabular}

Preconditions for the legitimacy of international institutions are comparative benefits and broad transparency. Further, I suggest three different standards of legitimacy for international institutions according to their level of rule-setting competences consisting of graded human rights, accountability, and participation standards. The reason is that there is a shift of authority from states to international institutions which, if unchecked, has the potential to undermine individual and collective autonomy.

\section{Human Rights, Accountability, and Participation Standards}

Before I discuss the standards for the different levels in turn, let me explain why certain human rights, accountability, and participation standards are appropriate for international institutions and the terminology used particularly for the human rights obligations.

The standard distinction for human rights obligations of states is between obligations of respect, protect, fulfill (Eide, 1987). ${ }^{8}$ The obligation to respect only demands to abstain from human rights violations, to protect includes the measures necessary to prevent others from violating human

\footnotetext{
${ }^{8}$ See Shue (1980) for a detailed discussion of these different human rights obligations using slightly different terminology.
} 
rights, while to fulfill human rights means to take the measures necessary to ensure opportunities to obtain satisfaction of those needs, recognized in human rights. Particularly in political conceptions of human rights, they are understood to apply to states as the primary duty bearers (e.g. Rawls, 1999; Beitz, 2009). Human rights can be understood as protecting the basic conditions for autonomy. This protection from "standard threads" is attributed to states because it requires generalized institutionalization which only states can provide and because the political power of states is itself a threat to autonomy, thus they are held to human rights standards. However, because states have delegated competences to international institutions, the latter gain authority and need to share the corresponding burdens. There are two main reasons for this: first, states should not be allowed to avoid their human rights obligations by delegating authority to the international level. Insofar as states act through international institutions, they need to be held responsible on that level too, so that they cannot engage in a two-level game. Second, if international institutions have the capacity to diminish states' capacity to fulfill their human rights obligations, this shift in authority needs to be captured. Human rights obligations have been used to control the threat that political power poses for individuals and groups, while the new distribution of political power makes it necessary that international institutions are held to certain human rights standards so that no vacuum for protection from the threats develops. In this understanding, states remain the primary duty bearers of human rights but complementary duties apply to international institutions.

Regarding the terminology, I will use the obligations to respect, protect, and fulfill human rights as defined by Eide (1987). However, international institutions cannot be expected to fulfill human rights, since they lack the necessary resources. Yet, in addition to the three standard obligations, I propose an additional category: namely to promote human rights, which falls in its demandingness between respecting human rights, as abstaining from violations, and protecting human rights from violations by others. To promote human rights requires international institutions to ensure that they do not undermine human rights related to their institutional purpose through their rule-setting and application. It requires a credible effort to prevent their rules from having negative effects on human rights, against the background of a reasonable effort to acquire knowledge about the risks involved. This duty differs from the protection of human rights because it does not require enforcement mechanisms. For medium-level institutions, this active duty to promote - not just a requirement to abstain from violations - applies, since they are exercising authority over either a medium-wide scope or a sensitive domain. Christina Lafont similarly assigns human rights responsibilities to certain international institutions: "the obligation to ensure that the regulations they implement in the pursuit of their respective goals (e.g. trade liberalization, financial stability, economic growth, etc.) do not hamper the protection of human rights worldwide" (2010: 203). She 
calls this a duty of respect but makes clear that it is not simply a negative duty to abstain from actions rooted in the institution's mission.

Participation standards are required for similar reasons to ensure that the rise of political power on the international level does not lead to diminished political autonomy. Participation is mainly required of institutions with high competences and direct rule applicability such as the European Union as they can sidestep domestic democratic decision-making. For institutions with lower levels of political power, the transfer of competences is not so drastic as to require participation. However, their power should still be controlled through forms of accountability. In particular, for institutions with medium rule-setting competences but only with indirect rule applicability, this can be achieved through contestation mechanisms as these allow those subjected to highlight problems with rules. While accountability standards such as contestation or representation through state channels cannot guarantee full political autonomy, they can nevertheless help to protect the condition of autonomy, in particular, an adequate range of options by enabling the articulation of interests and highlighting the problems caused by certain rules. The standards of participation and accountability for international institutions are supposed to protect the conditions of individual and political autonomy; therefore, they either protect the capacity of states to provide it or control the new political power on the international level that replaces the domestic one. Overall, this view is based on the complementarity of legitimacy standards for international institutions and political participation on the domestic level to protect autonomy.

\section{Preconditions of Legitimacy}

As minimal requirements of legitimacy, international institutions need to generate comparative benefits. In my proposed understanding, output is a minimal condition for institutional legitimacy because the coordinative aim of institutions fails if they produce no beneficial output at all. It is a relevant measure in comparison not only to non-institutional alternatives, but also to other feasible institutional alternatives. Therefore, what is required is "comparative benefit" (Buchanan and Keohane, 2006: 422; Pogge, 2008: 19). The first comparison to the non-institutional alternative makes it a precondition of an institution's legitimacy that the social purpose for which it was created is served better by that institution than by no institution at all. However, such a noninstitutional status is a questionable normative baseline because it may include significantly problematic facts such as severe human rights violations (Pogge 2007: 38-41). To establish that an institution creates binding rules, it also has to produce benefits superior to those that feasible alternative institutions could produce. Buchanan states that legitimacy does not require an institution to do "a better job than all the other feasible alternative institutions" (2013: 178). 
Legitimacy cannot permit the option of other clearly superior and feasible institutions since this would undermine its function to decide between different possible institutional alternatives and lead to a stability problem and undermine the metacoordination function of legitimacy standards.

To be clear, this does not mean that an institution has to be the ideal one, as it may not be feasible. Another problem that arises if only non-institutional but not feasible institutional alternatives are considered to establish legitimacy (i.e. institutions would have to provide some benefit but not the best feasible one) is that it would lead to a status quo bias. New insights and options for improvement would not need to be taken into account as long as the institution does some good. Therefore, such a concept of legitimacy would not provide a critical standard to improve institutions. The fact that feasible institutional alternatives are relevant for our assessment of legitimacy is also visible in the shift of legitimacy standards over time, as the example of changing political inclusion shows. Eighteenth-century democracies where only men had voting rights were not illegitimate, but are generally considered to be so today.

Regarding the metacoordination function, it also seems clear that the feasibility of a superior institution is problematic for the reasons to comply with the less beneficial one. However, this might not be drastic enough to drop the less beneficial institution below the sufficiency limit of legitimacy. To establish this might require assessing how the benefits are distributed, which goes beyond the scope of this paper, but also a less controversial issue, namely transition costs (Keohane, 2011). Transition costs - such as insecurities, new learning processes or inefficiencies - need to be subtracted from the benefits that an alternative feasible institution might grant in comparison with an existing one. Already having coordinated in one institution is an achievement that counts in favor of existing institutions. Therefore, an institution need not be better than all other feasible alternatives, but if another feasible institution is considerably better, so much that it would warrant the requisite transition costs, it might challenge the legitimacy of the existing institution.

One might object that the problem with taking the feasibility of alternative institutions as a baseline for legitimacy is that feasibility is epistemically too uncertain. This is particularly true since feasibility here cannot just mean strict logical or natural law restrictions, but is related to what Gilabert and Lawford-Smith call soft feasibility constraints (Gilabert and Lawford-Smith, 2012). These include economic, institutional, cultural, and perhaps even psychological constraints. There are several difficulties associated with this. Particularly important for the question of legitimacy is that such soft feasibility constraints are agent- and time-relative. Depending on the actions that are taken now, the feasibility of certain institutions can change at a later point in time. To make feasibility judgments for the purpose of legitimacy requires determining the relevant agent and timeframe. On this basis I argue that alternative institutions have to be clearly feasible, i.e. very probable for an agent to bring about in a specific timeframe, to call the legitimacy of existing 
institutions into question. They have to be clearly feasible so as to avoid the risk of falling back to the non-institutional level, which could happen if a less beneficial institution is no longer complied with, but the alternative cannot be achieved. Yet, since the epistemic insecurity is severe, it is easier to make these assessments retrospectively rather than prospectively. For example, nowadays universal suffrage is a standard that almost all states uphold. If a state were to now abandon voting rights for women, it would be judged as illegitimate, since its previous existence creates a strong presumption that universal suffrage is feasible.

What is at stake in the discussion about legitimacy are content-independent reasons to comply. If an institution is judged as illegitimate because there are better feasible alternatives, or for other reasons, those subjected to its rules do not have to comply with them just because the institution issues them (there might still be other reasons to comply though) and outsiders do not have reasons not to interfere. This non-compliance and interference with the institution can lead to abolishing the whole institution. ${ }^{9}$ Alternatively, reforms of the institution might be undertaken if these are easier to establish than a new institution; however, it is important that this still does not mean that reasons to comply are given. Demand for reforms can also arise if an institution falls into the space of being legitimate but not fully just. However, in this case, compliance is still demanded. To conclude, these comparative benefit and feasibility evaluations are surely not easy to make, and how to know or decide about them requires further discussion. The point here is purely conceptual, namely that comparative benefits are the minimal requirement for legitimacy, but feasible institutional alternatives can elevate that requirement.

The second precondition for legitimacy, "broad transparency", is necessary to make international institutions assessable in an environment of high informational inequalities. Buchanan and Keohane (2006) describe "broad transparency" as "epistemic virtues that facilitate the ongoing critical revision of its goals, through interaction with agents and organizations outside the institution" (2006: 406). I agree that "narrow transparency", consisting in accessible information at a reasonable cost to those affected by an institution, is insufficient as a standard of legitimacy. Therefore, broad transparency for third parties is required to protect those who fall under the rules of an institution, but who do not have the means to access or assess the relevant information.

\section{Low Level of Competences}

As for low-competence institutions, their competences have only a restricted scope, coordinative or technical domain, low impact and mediated applicability of rules, through the implementation of

\footnotetext{
${ }^{9}$ Whether this allows for resistance or revolution will further depend on questions of justified violence.
} 
states. Their capacity to affect individual lives is therefore not so severe. Nonetheless, the purpose of these institutions also has to be regulated by minimal substantial requirements. To not persistently violate the basic human rights is a minimal condition for the legitimacy of international institutions. This is necessary even at this low level, because basic human rights are fundamental preconditions for the equal autonomy of individuals. Institutions that violate the basic human rights of those subjected or affected outsiders cannot be justified reciprocally, and, therefore, cannot generate reasons to comply or not to interfere with them. The minimal form of accountability that institutions with low competences should meet is the ongoing consent of democratic states as a democratic accountability channel (Buchanan and Keohane, 2006: 415). This is not a necessary condition for legitimacy; rather, it is an indicator for legitimacy, as Buchanan and Keohane (2006) outline. If no or very few democratic states approve of an international institution, this indicates that the institution might not be legitimate. Participation rights for institutions with low competences cannot be required for technical and coordinative issues. Since these institutions have a very limited range of rule-setting competences and no direct applicability, the risks that they pose to autonomy can be controlled by standards of respecting human rights in combination with the ongoing consent of democratic states (as well as the minimal requirements of broad transparency and comparative benefit). These restricted standards for participation build on the idea that states are the primary locus of participation, and only if the political power of international institutions threatens the political autonomy realized at the domestic level are additional participatory standards necessary.

\section{Medium Level of Competences}

International institutions holding a medium level of competences and indirect applicability of their rules should promote human rights in their area of rule-setting. The obligation to promote requires the institution to take positive action not to undermine the enjoyment of human rights and therefore to uphold equality in their rule-setting and application. It consists of the adoption of a human rights based approach to the work of the institution, which includes: first, acquiring knowledge about how the institution's rules can affect human rights; second, making a credible effort not to undermine human rights by paying attention to equality, non-discrimination, and the inclusion of disadvantaged groups; and third, not diminishing the state's necessary capacity to fulfill its human rights obligations. In particular, the institution needs to make a credible active effort in the rulesetting not to impact on human rights negatively. The promotion of human rights concerns, however, only those rights relevant to the institution's respective purpose, not all human rights. Otherwise, all international institutions would be required to be human rights organizations. The promotion of human rights connected to the institution's purpose is necessary to achieve 
institutional integrity and to reduce the risk of undermining their own goals by making sure that their own rules and action do not impede human rights. The discussion about the World Bank's responsibility to take into account human rights relevant to its goal of sustainable development - in particular, to avoid displacement and to protect the rights of indigenous peoples - is a case in point. Another pertinent example is the World Trade Organization (WTO) and whether it leaves its member states' capacity to fulfill their human rights obligations intact. Steven Ratner also discusses this issue in respect of limiting the state's policy space (2015: 327ff.). ${ }^{10}$ Regarding the International Monetary Fund (IMF), Ratner argues that justice turns on whether it harms or does not harm human rights (2015: 259). This might sound as if he is arguing for simply respecting human rights. However, in his discussion of the IMF, Ratner focuses on economic human rights, particularly the rights to food and health. In this context, harming cannot be captured by the representatives of the institution abstaining from violations. Rather, it is about the promotion of human rights - namely whether its rules and decisions undermine human rights either by restricting the state's necessary capacity to fulfill its human rights obligations or by knowingly opening up room for or even incentivizing others to engage in actions that have negative effects on human rights. For this legitimacy standard, it is relevant whether the power of an institution is restrained by human rights standards in its rule-setting. Embedding human rights concerns in this process is relevant for an institution's legitimacy even if particular unforeseen circumstances or the influence of other actors might lead to other outcomes. The promotion of human rights through international institutions is necessary insofar as the delegation of competences from states to international institutions has created a shift in authority. This authority comes with the respective responsibilities to protect the equal autonomy of individuals, as this might no longer be possible for states alone. Yet, the specific requirement for medium-level institutions is in fact hard to determine since their purposes and functions vary so widely.

The capacity to revise the terms of accountability, a standard suggested as a criterion by Buchanan and Keohane (2006), allows the terms of accountability to be adapted with changing institutional competences or goals (Buchanan and Keohane, 2006: 432). The revisability of terms of accountability is the ideal standard for institutions with medium competences, but it is hard to verify because institutions also need to remain stable. The necessary level of revisability is therefore very difficult to determine in practice. The minimal standard of accountability required should rather consist of an institutionalized contestation mechanism for individuals or groups, to contest a specific action or the rules that they are affected by (or subjected to). One of the main problems for

${ }^{10}$ For a perceptive discussion of the relation between human rights and the WTO, see Breining-Kaufmann (2005). 
the accountability of international institutions is determining to whom they should be accountable (cf. Grant and Keohane, 2005). Alongside the requirement of broad transparency, this should establish a minimal level of accountability. In particular, it should make the terms of accountability receptive enough to include as accountability-holders all the people affected by the institution's rules and therefore to significant changes in their range of options. This is a weaker form of accountability than direct participation, but nevertheless requires some form of court or dispute settlement mechanism.

In terms of participation, equal democratic rights cannot be demanded at this level of competences because, also at this level, rules have no direct effect and are therefore mediated through states. However, deliberation rights should be adopted in order to make the interests of the subjected individuals or states accessible and publicly known. Put plainly, those affected by the rules of an institution should be consulted, which should be guaranteed by contestation and deliberation rights. However, if a state is politically or economically required to implement such rules, the impact of the institution is the same as if it had direct effect and therefore should be required to fulfill the standards of high-level competence institutions.

\section{High Level of Competences}

The distinguishing feature of institutions with high-level competences is that their rules have direct effect. Regarding human rights, international institutions with high rule-setting competences and direct effect should meet almost the same standards as states, namely the protection of human rights. The protection of human rights requires states to establish judicial and enforcement measures to protect individuals and groups against human rights abuses. If an institution that is engaged in setting rules directly applicable to individuals refrains from the protection of human rights, it can undermine the protection by states. In order to render this protection of human rights binding, it should also include an enforcement mechanism. The requirements in terms of human rights legitimacy for such institutions are almost equivalent to those of states. Specifically, it must enforce human rights where its member states fail to do so.

For institutions with a high level of competences, accountability should be secured through national and international democratic representatives in the institution. The main reason why a form of equal democratic participation is necessary on this level is because the rules have direct effect. If these rules are not themselves established in a way that respects the equal moral status of those subjected, democracy on the domestic level is undermined without an adequate substitute. Assuming that states are not abolishable in the short or medium term and that they currently provide the most effective participation and rights structures, to guarantee participation within high-level 
competence, institutions need to take them into account. The best way to do so is through a voluntary association of democratic states, since the democratic constitution of the member states is a precondition for democratization at the international level (cf. Christiano, 2010). Such states can be expected to represent the interests of their citizens. The democratic states are of normative value as realms of justice since the expression of the collective autonomy of the individuals and their political institutions guarantee their rights and welfare. Institutionally, the theory of multilateral democracy or "demoicracy" outlines how international relations in such a democratic association should be organized so as to be democratic themselves (see Cheneval, 2011; Nicolaïdis, 2004). This includes representative institutions for both states and citizens. Multilateral democracy is constructed for international organizations, such as the EU, which are characterized by a high degree of competences and broad legislative powers.

The influence of non-democratic states in such institutions is not obvious for democratic states since they should respect the democratic decision-making in other democratic states as forms of political autonomy, which is not the case for non-democratic states. Regarding non-democratic states, the requirement for high-level competence institutions is to not undermine the conditions of democratic decision-making within these states. The legitimacy standards that institutions with high-level competences and both democratic and non-democratic institutions need to fulfill requires further discussion.

\section{CONCLUSION}

The variety in function and competences of international institutions requires an account of legitimacy that can capture these differences and set the standards of legitimacy accordingly. The concept of legitimacy presented in this paper is based on the need to justify political power understood as the capacity to restrict autonomous life choices through rule-setting. International institutions are legitimate if they provide content-independent reasons to comply and not to interfere with the institution. The more rule-setting competences an institution has, the stronger the legitimacy standards it needs to fulfill.

This analysis of international legitimacy provides new insight into the normative requirements of different international institutions. On the basis of this account, systematic critical evaluation of international institutions with specific suggestions for reform is possible without completely revoking compliance with an institution. The graded standards of legitimacy developed herein allow for a more fine-grained evaluation of the legitimacy of international institutions. In order to examine the legitimacy of a particular institution, it is necessary to analyze its specific purpose, which requires further research. 


\section{REFERENCES}

Adams NP (2019) Legitimacy and institutional purpose. Critical Review of International Social and Political Philosophy 0(0): 1-19.

Adams NP, Scherz A and Schmelzle C (2019) Legitimacy beyond the state: institutional purposes and contextual constraints. Critical Review of International Social and Political Philosophy $0(0): 1-11$.

Applbaum AI (2010) Legitimacy without the Duty to Obey. Philosophy \& Public Affairs 38(3): 215-239.

Archibugi D and Held D (1995) Cosmopolitan Democracy: An Agenda for a New World Order. Cambridge: Polity Press.

Beetham D (1991) The Legitimation of Power. Atlantic Highlands, N.J: Humanities Press International.

Beitz CR (2009) The Idea of Human Rights. Oxford: Oxford University Press.

Besson S (2014) The legitimate authority of international human rights. In: Føllesdal A, Schaffer JK, and Ulfstein G (eds) The Legitimacy of International Human Rights Regimes. Legal, Political and Philosophical Perspective. Cambridge: Cambridge University Press, pp. 3283.

Blake M (2001) Distributive Justice, State Coercion, and Autonomy. Philosophy \& Public Affairs 30(3): 257-296.

Breining-Kaufmann C (2005) The Legal Matrix of Human Rights and Trade Law: State Obligations versus Private Rights and Obligations. In: Cottier T, Pauwelyn J, and Burgi E (eds) Human Rights and International Trade. Oxford: Oxford University Press, pp. 95-136.

Buchanan A (2010) Legitimacy of International Law. In: Besson S and Tasioulas J (eds) The Philosophy of International Law. Oxford: Oxford University Press, pp. 79-96.

Buchanan A (2013) The Heart of Human Rights. Oxford, New York: Oxford University Press.

Buchanan A (2018) Institutional Legitimacy. In: Sobel D, Vallentyne P, and Wall S (eds) Oxford Studies in Political Philosophy. Oxford University Press, pp. 53-78. 
Buchanan A and Keohane RO (2006) The Legitimacy of Global Governance Institutions. Ethics \& International Affairs 20(4): 405-437.

Cheneval F (2011) The Government of the Peoples: On The Idea and Principles of Multilateral Democracy. New York: Palgrave Macmillan.

Christiano T (2010) Democratic Legitimacy and International Institutions. In: Besson S and Tasioulas J (eds) The Philosophy of International Law. Oxford: Oxford University Press, pp. 119-138.

Christiano T (2012) The Legitimacy of Internatinoal Institutions. In: Marmor A (ed.) The Routledge Companion to Philosophy of Law. Routledge, pp. 380-93.

Eide A (1987) The New International Economic Order and the Promotion of Human Rights. Report on the Right to Adequate Food as a Human Right. E/CN.4/Sub.2/1987/23. United Nations.

Føllesdal A and Hix S (2006) Why There Is a Democratic Deficit in the EU: A Response to Majone and Moravesik. JCMS: Journal of Common Market Studies 44(3): 533-562.

Forst R (2012) The Right to Justification: Elements of a Constructivist Theory of Justice. Columbia University Press.

Forst R (2015) Noumenal Power. Journal of Political Philosophy 23(2): 111-127.

Gilabert P and Lawford-Smith H (2012) Political Feasibility: A Conceptual Exploration. Political Studies 60(4): 809-825.

Grant R and Keohane RO (2005) Accountability and Abuses of Power in World Politics. American Political Science Review 99(1): 29-43.

Habermas J (1996) Between Facts and Norms: Contributions to a Discourse Theory of Law and Democracy. Cambridge, Mass.: MIT Press.

Held D (1995) Democracy and the Global Order: From the Modern State to Cosmopolitan Governance. Stanford, Calif.: Stanford University Press.

Hershovitz S (2003) Legitimacy, democracy, and Razian authority. Legal Theory 9(03): 201-220.

Howse R and Nicolaïdis K (2003) Enhancing WTO Legitimacy: Constitutionalization or Global Subsidiarity? Governance 16(1): 73-94. 
Keohane RO (2011) Global Governance and Legitimacy. Review of International Political Economy 18(1): 99-109.

Lafont C (2010) Accountability and global governance: challenging the state-centric conception of human rights. Ethics \& Global Politics 3(3): 193-215.

Locke J (1980) The Second Treatise of Government. Indianapolis, Ind.: Hackett.

Majone G (2000) The Credibility Crisis of Community Regulation. JCMS: Journal of Common Market Studies 38(2): 273-302.

Mitchell RB (2008) Evaluating the performance of environmental institutions: What to evaluate and how to evaluate it. Institutions and environmental change: Principal findings, applications, and research frontiers 79: 83-84.

Nicolaïdis K (2004) The New Constitution as European 'Demoi-cracy'? Critical Review of International Social and Political Philosophy 7(1): 76-93.

Patomäki H (2003) Problems of Democratizing Global Governance: Time, Space and the Emancipatory Process. European Journal of International Relations 9(3): 347-376.

Pettit P (1997) Republicanism. A Theory of Freedom and Government. Oxford; New York:

Clarendon Press; Oxford University Press.

Pettit P (2012) On the People's Terms: A Republican Philosophy of Democracy. Cambridge: Cambridge University Press.

Pogge T (2007) Freedom from Poverty as a Human Right: Who Owes What to the Very Poor? Oxford University Press.

Pogge T (2008) World Poverty and Human Rights: Cosmopolitan Responsibilities and Reforms. Second Edition. Cambridge: Polity Press.

Ratner SR (2015) The Thin Justice of International Law: A Moral Reckoning of the Law of Nations. OUP Oxford.

Rawls J (1971) A Theory of Justice. Cambridge, Mass.: Belknap Press of Harvard University Press. Rawls J (1999) The Law of Peoples. Cambridge, Mass.: Harvard University Press.

Raz J (1986) The Morality of Freedom. Oxford: Oxford University Press. 
Raz J (2006) The Problem of Authority: Revisiting the Service Conception. Minnesota Law Review (90): 1003-1044.

Reglitz M (2015) Political Legitimacy Without a (Claim-) Right to Rule. Res Publica: 1-17.

Shany Y (2014) Assessing the Effectiveness of International Courts. OUP Oxford.

Shue H (1980) Basic Rights: Subsistence, Affluence, and U.S. Foreign Policy. Princeton University Press.

Squatrito T, Young OR, Føllesdal A, et al. (eds) (2018) The Performance of International Courts and Tribunals. Cambrdige University Press.

Stein E (2001) International Integration and Democracy: No Love at First Sight. American Journal of International Law 95(3): 489-534.

Tasioulas J (2010) The Legitimacy of International Law. In: Besson S and Tasioulas J (eds) The Philosophy of International Law. Oxford University Press, pp. 97-116.

Viehoff D (2011) Debate: Procedure and Outcome in the Justification of Authority. Journal of Political Philosophy 19(2): 248-259.

Von Bogdandy A and Venzke I (2012) In whose name? An investigation of international courts' public authority and its democratic justification. European Journal of International Law 23(1): 7-41.

Weber M (1964) The Theory Of Social And Economic Organization. New York: Simon and Schuster.

Zürn M, Binder M and Ecker-Ehrhardt M (2012) International authority and its politicization. International Theory 4(1): 69-106. 